\title{
Campanhas eleitorais e cobertura mediática: abordagens teóricas e contributos para a compreensão das interações entre política e media
}

A perspectiva dos estudiosos em relação ao papel dos media no processo político tem sofrido alterações nas últimas décadas. É possível identificar posições em que os media são vistos como um veículo mais ou menos passivo de mensagens e posições que defendem que os media se tornaram um ator político, cuja ação pode ter implicações em momentos tão diversos como a governação diária ou as campanhas eleitorais.

Alguma literatura mais recente sobre o tema tem sugerido que os media estão a tomar uma parte ativa na representação pública da política, modelando a agenda do discurso político, e influenciando com as suas próprias preferências as controvérsias e os debates políticos (Bennett e Entman, 2001; Patterson, 2000; Iyengar e Reeves, 1997). Alguns autores sugerem mesmo que a crescente importância dos media levou à emergência de um novo tipo de democracia, uma "media democracy", que substitui a anterior "party democracy" (Hess, 1988; Manin, 1996; Meyer, 2002). Esta designação pretende chamar a atenção para um novo tipo de democracia, na qual a lógica dos media influencia o processo político, o que leva alguns autores mais radicais a defender que, em certa medida, as próprias instituições políticas estão a perder o controle da política.

Os estudos sobre o impacto político dos media nas democracias modernas têm-se focado sobretudo em duas grandes áreas de investigação: por um

* É professora do Departamento de Ciências da Comunicação da Universidade Nova de Lisboa (Lisboa, Portugal). E-mail: susanapsalgado@gmail.com. 
lado, os efeitos dos media nas atitudes dos cidadãos e na participação, o que inclui naturalmente o comportamento eleitoral e, por outro, a denominada "americanização" das campanhas eleitorais como uma resposta dos partidos políticos ao ambiente eleitoral em mudança.

O denominado processo de americanização das campanhas pretende explicar uma tendência registada em outros países, tão diferentes como a Suécia ou a Argentina, por exemplo, a seguir as técnicas e métodos das campanhas norte-americanas (Swanson e Mancini, 1996). Nesse sentido, verificam-se, um pouco por toda a parte, fenômenos como um maior afastamento entre cidadãos e partidos políticos, uma crescente personalização da política impulsionada pela influência dos media, e em particular da televisão, na política e na sociedade em geral, e um recurso progressivo a estruturas de comunicação e imagem, com o objetivo de cultivar de forma constante o apoio da opinião pública. Esta última característica sugere ainda que a produção e a divulgação da informação necessária aos processos de decisão política são definidas com a ajuda de intermediários, como é o caso dos consultores, dos spin doctors e dos especialistas em comunicação, que aconselham os políticos, ajudando a selecionar a informação que deve ser divulgada à população, bem como qual o timing e a forma mais adequada de o fazer.

No que diz respeito à influência das campanhas no comportamento eleitoral, Mughan (1978) explica que os primeiros estudos realizados apontam para a existência de padrões de elevada estabilidade na escolha do voto e para a conclusão de que, geralmente, são poucos os leitores que mudam de opinião no decurso da campanha eleitoral. Como consequência, os efeitos da campanha foram identificados mais ao nível do reforço do que propriamente da transformação das predisposições de voto. Este tipo de efeitos foi durante algum tempo considerado como pouco relevante, mas estudos de outros autores, como Noëlle-Neumann (1973), chamaram a atenção para a importância que tem para a opinião pública a confirmação de determinados pontos de vista e percepções, especialmente quando todos os órgãos de informação assumem uma posição consonante, isto é, uma posição muito similar, limitando o pluralismo e a diversidade de ideias, e geralmente apresentando uma das posições como a mais correta.

Por outras palavras, os estudos realizados no passado apontavam para a inexistência de efeitos dos media e das campanhas porque procuravam sobretudo os efeitos de conversão e de alteração do sentido de voto, ignorando 
outros possíveis efeitos tão ou mais importantes, como é o caso do reforço, da ativação, ou da manutenção. Estes últimos são efeitos que funcionam sobretudo a médio e longo prazo, porque a sua ação se desenvolve ao nível da construção de imagens e percepções, do desenvolvimento de predisposições no sentido de determinada preferência partidária ou posicionamento ideológico, ou do reforço de ideias e opiniões, muitas vezes agindo de forma não inteiramente consciente para os indivíduos.

A ideia de que os indivíduos desenvolvem resistências à propaganda e de que a sua exposição às mensagens dos políticos e dos media é seletiva - por exemplo, comprando jornais ou assistindo a programas televisivos que são mais compatíveis com as suas preferências partidárias - reforça a importância deste tipo de efeitos que são mais difíceis de identificar, mas ao mesmo tempo representam formas mais eficazes de influência, porque se desenvolvem a um nível mais estrutural. São os casos, por exemplo, da construção de contextos, da definição da envolvente política e social, do fornecimento de padrões de interpretação para os temas e para os atores políticos, e do clima de opinião que é transmitido pelos media.

As pesquisas sobre a função de agendamento dos media iniciadas por McCombs e Shaw em 1972 e, mais tarde, o desenvolvimento do conceito de enquadramento, para explicar um outro tipo de efeitos dos media sobre a realidade, apontam para a confirmação da existência de efeitos indiretos e para a importância dos media na estruturação da realidade. Depois da conclusão de que os media, através da sua função de agenda-setting, determinam os assuntos sobre os quais as pessoas pensam e a importância que lhes deve ser atribuída, McCombs, Shaw e Weaver (1997) sugeriram que o enquadramento é, na realidade, uma extensão do agendamento, porque pretende chamar a atenção para o impacto que a interpretação que os media fazem dos eventos, dos fatos e das personalidades tem nas audiências.

Os estudos sobre o agendamento alargaram o conhecimento sobre os efeitos dos media, mas ignoraram o estudo de como as diferentes formas de apresentação da informação podem afetar o processo de formação da opinião pública (Porto, 2004). Desta forma, é necessário prestar atenção não apenas aos temas que os media enfatizam, mas também ao modo como esses temas são apresentados. As pesquisas sobre o conceito de enquadramento alertaram então para um outro nível de efeitos, e a principal preocupação passa a ser o estudo da influência da forma como a informação é apresentada. 
Após a compreensão das implicações do tratamento jornalístico da realidade, através do agendamento e do enquadramento, por exemplo, não é complicado perspectivar a influência indireta que os media podem ter na cobertura mediática da política em geral e nos contextos de campanha eleitoral em particular. Essa influência pode significar o tratamento de temas que são mais benéficos para uns candidatos do que para outros e a escolha dos partidos e dos candidatos que recebem mais cobertura noticiosa e os que são silenciados, influenciando assim a sua visibilidade através da exposição mediática. Pode ainda representar o tratamento diferenciado através de uma cobertura positiva ou negativa, influenciando a imagem que os eleitores constroem das diferentes candidaturas, e podendo mesmo, em alguns casos, passar a imagem de que uma candidatura já venceu as eleições antes do dia do voto.

\section{Campanhas eleitorais: algumas definições possíveis e objetivos}

De uma forma geral, as campanhas podem ser definidas como uma série de eventos planejados para comunicar determinadas mensagens a uma ou várias audiências, com o intuito de ganhar o apoio dessas audiências, podendo, por isso, ser iniciadas por uma série de atores, desde os comerciais aos políticos, consoante os objetivos e os contextos. Dentro das campanhas, destaca-se a importância das campanhas eleitorais, que são momentos privilegiados de comunicação na vida política, e que visam mobilizar e convencer os eleitores.

As campanhas eleitorais são o que Dayan e Katz (1992) denominam de media events, o que significa um acontecimento programado, limitado no tempo e no espaço, que apresenta um grupo ou uma personalidade, tem uma significação dramática ou ritual e possui ainda uma força específica que nos obriga a olhar para esse acontecimento.

As campanhas eleitorais pressupõem um feedback entre os organizadores e o público-alvo e são um processo que ocorre num sistema político e social marcado por diversos fatores, como o nível de desenvolvimento socioeconômico e democrático, o que inclui a liberdade de expressão e imprensa e o grau de autonomia dos jornalistas. As campanhas eleitorais podem, assim, ser vistas como esforços organizados para mobilizar e convencer através da informação e da persuasão e incluem diferentes elementos que se interligam, agindo uns sobre os outros, e que têm influência sobre o resultado. Um dos elementos é o contexto das instituições, como o sistema político e legal e a 
estrutura do sistema mediático, por exemplo, que são diferentes de país para país. Concretamente, referimo-nos ao papel do Estado, ao peso do serviço público nos órgãos de informação, ou às definições legais que regulam as eleições, a competição entre os partidos, a apresentação de candidaturas e as próprias campanhas.

Um segundo elemento a considerar são os objetivos estratégicos que os candidatos e organizadores da campanha definem e procuram comunicar. Esses objetivos variam consoante o contexto político e econômico-social do país na altura da eleição, mas são influenciados sobretudo pela dimensão e pela natureza dos partidos e candidatos em competição.

Podemos sintetizar em três os tipos mais usuais de objetivos: um primeiro tipo de objetivo prende-se com a difusão das ideias do candidato ou do partido, que acontece com maior probabilidade se o partido não tem hipóteses de ganhar as eleições, nem de obter um bom resultado. Neste caso, a campanha pode ser utilizada para outros fins: aumentar a popularidade, melhorar a imagem, ou promover e difundir ideias. Um outro tipo de objetivo é a obtenção de um bom resultado. Um bom resultado normalmente é uma boa votação, maior do que a obtida nas eleições anteriores, o que dará ao partido maior influência política. Mais assentos no Parlamento, mais atenção da parte da comunicação social, maior peso nas decisões políticas do país, em suma, mais prestígio no contexto político-partidário. Por fim, um terceiro tipo de objetivo é o de vencer as eleições. A obtenção de maioria absoluta ou relativa poderá ser outro objetivo relacionado a fixar.

Consoante os objetivos estabelecidos, cada partido político (ou candidato) define a estratégia que deverá seguir durante a campanha eleitoral. A definição da estratégia pressupõe tomadas de decisão sobre elementos políticos de comunicação: por que tipo de mensagem optar? Esta decisão inclui a preocupação de desenvolver mensagens adequadas às audiências e aos suportes, mas coerentes com a imagem e os objetivos dos atores políticos. Depois, como comunicar com os diferentes segmentos do eleitorado? A que segmento ou segmentos do eleitorado se dirigir preferencialmente? Estas são apenas algumas das questões que se levantam ao planejar a estratégia.

Desta forma, os atores políticos, após a definição dos objetivos e das mensagens que pretendem comunicar ao eleitorado, necessitam de um outro elemento para efetivar a sua comunicação eleitoral: os canais de comunicação, que podem ser diretos ou mediados. 
Os canais de comunicação diretos são aqueles meios que permitem aos atores políticos comunicar diretamente com o eleitorado apenas com a mediação do suporte. É o caso dos websites dos partidos, do YouTube, ou das ferramentas on-line que permitem a interação direta entre eleitores e candidatos - ou o seu staff -, como o email ou o Facebook, e outros programas semelhantes, como é também o caso dos Programas de Governo ou Manifestos Presidenciais (no caso Português) e dos espaços gratuitos de propaganda eleitoral nos media, como o Direito de Antena em Portugal, ou o Horário Eleitoral Gratuito no Brasil, por exemplo.

Os outros canais de comunicação são aqueles que permitem aos partidos e aos candidatos transmitir a sua mensagem com a mediação dos jornalistas nos órgãos de informação de massa, isto é, a rádio, a televisão e a imprensa escrita. Esta possibilidade permite um menor controle sobre a mensagem final, mas apresenta vantagens inegáveis: permite chegar a um maior número de pessoas (as audiências destes meios) e o trabalho jornalístico atribui um cunho de veracidade ao discurso político, que passa de simples propaganda política a informação política. No entanto, também estes canais de comunicação com o eleitorado apresentam deficiências, que decorrem do próprio trabalho jornalístico, porque este geralmente favorece a realização de coberturas estratégicas e negativas da política e dos políticos, acabando por provocar uma espiral de cinismo, como referem Cappella e Jamieson (1997), explicada com mais detalhe um pouco mais adiante. Mas existem outros tipos de limitações, como as que podem ser causadas pela possibilidade de controle do trabalho dos jornalistas por agentes políticos, sociais e econômicos.

Por fim, é necessário considerar ainda um outro elemento, que é a questão do impacto e dos efeitos possíveis das mensagens dos políticos e dos jornalistas nos indivíduos e no comportamento eleitoral. Este aspecto é um dos mais investigados, pois a compreensão dos fenômenos de persuasão e de influência tem particular interesse para todos os atores envolvidos no processo, desde os primeiros tempos em que os media de massa começaram a ser usados para transmitir propaganda e informação política.

A maior parte dos estudos sobre as campanhas eleitorais centram-se sobretudo num ou noutro aspecto consoante sejam realizados por investigadores oriundos da ciência política ou da comunicação e dos estudos de media. Todavia, a área de estudos da comunicação política tem-se vindo a impor 
e começaram a surgir estudos que tentam incorporar todos os diferentes elementos na investigação, de forma a compreender como uns agem sobre os outros, as suas interações, e que tipo de influências sofrem os diferentes atores (políticos, jornalistas, eleitores).

Quando se estuda a campanha eleitoral sob a perspectiva da comunicação política, é essencial incluir todos os elementos e interpretar as suas interações: os sistemas políticos e mediáticos, os atores políticos e seus objetivos, os canais de comunicação e o impacto da informação e das mensagens políticas nos eleitores.

Os eleitores tomam contato com a campanha eleitoral através dos meios de comunicação, e o objetivo último do emissor da mensagem política será o impacto positivo no eleitorado - receptor. Os partidos políticos e os candidatos, ao planejar e ao implementar as suas campanhas eleitorais, regem-se pelo prévio estabelecimento dos seus objetivos para aquela eleição em particular, que podem ser a obtenção do maior número possível de votos, maior que o conseguido no último exercício eleitoral, ou mesmo vencer as eleições. Mas, é igualmente necessário selecionar os veículos (preferenciais e outros) da mensagem eleitoral. Por exemplo, decidir se faz sentido, no contexto particular da eleição, definir uma estratégia específica e uma equipe para alimentar os meios on-line, com o objetivo de desenvolver formas de comunicação direta com grupos específicos de eleitores. Este meio pode ser relevante para motivar as camadas mais jovens da população, ou para convencer o eleitorado flutuante, ou ainda aqueles eleitores mais desiludidos com as estruturas tradicionais, mais formais e hierárquicas dos partidos políticos.

Desta forma, o planejamento da campanha eleitoral já representa o resultado de todo um trabalho de elaboração da mensagem política, que deverá ser coerente com os objetivos do partido político ao concorrer a eleições. A estratégia de transmissão da mensagem através dos media tem de ser extremamente bem pensada e calculada, porque no caso da maior parte dos cidadãos o único contato que têm com a política, com os políticos e com as campanhas eleitorais é precisamente através dos media. Existem outras possibilidades de transmissão do discurso político, como o contato interpessoal e os comícios, mas mesmo estes são, cada vez mais, organizados para passar nos media, com a preocupação de conseguir bons momentos de campanha que os jornalistas depois amplificam através dos suportes e dos seus próprios comentários. 
As campanhas eleitorais cumprem, no domínio dos regimes democráticos, vários objetivos e podem influenciar os eleitores de diversas formas. Podemos começar por referir que um dos papéis da campanha é aumentar a saliência de um ou vários assuntos, que fazem parte das propostas de um partido, ou de um candidato. Interessa ao candidato colocar na agenda dos media e na agenda do público os assuntos com os quais pode convencer mais eleitores. Estes assuntos chave ajudam depois os eleitores a perceber as diferenças entre os diferentes partidos ou candidatos e a fazer a sua opção em termos de voto. Por outro lado, marcar a agenda desta forma serve ainda para forçar os adversários a tomar uma posição sobre estes assuntos, ou pode ajudar a demonstrar que os adversários não têm propostas estruturadas para esses temas.

Para além disso, ser o primeiro a tomar posição sobre um assunto importante para os eleitores pode ser uma importante mais-valia estratégica para a comunicação de campanha, porque, por um lado, os eleitores reconhecem-se no discurso do partido ou do candidato, que interpreta a situação, apresenta soluções e é solidário com os seus problemas e, por outro, ao tomar a dianteira, o partido ou o candidato evidencia ao mesmo tempo a fragilidade dos seus adversários. Esta situação de agendamento dos temas no espaço público faz com que o pensamento do eleitorado seja direcionado para um assunto, que é contextualizado pelas mensagens do político, particularmente se o assunto já era importante para os eleitores e se eles se identificam com as mensagens do partido (ou candidato).

Um outro objetivo das campanhas é, como seria de esperar, a persuasão. As mensagens são pensadas de forma a serem convincentes e são estudadas de forma a fazerem sentido no conjunto da estratégia eleitoral. Como, geralmente, os eleitores demonstram alguma resistência à propaganda, especialmente os que detêm níveis superiores de instrução escolar, uma das estratégias pode ser misturar a propaganda com a informação, ou dissimular a persuasão em fatos e apoios de membros proeminentes da sociedade.

Outro objetivo importante é promover o reconhecimento público dos partidos e dos candidatos. As campanhas são utilizadas para construir uma imagem positiva dos candidatos e funcionam como uma oportunidade para associar a imagem do candidato a propostas específicas, dar a conhecer a sua história, o seu desempenho profissional no passado, as suas ideias para o país. Toda esta informação será depois utilizada pelos eleitores para decidirem qual o candidato que, na sua opinião, desempenhará melhor o cargo. 
As campanhas têm ainda a função de mobilização dos apoiantes e simpatizantes do partido, o que ajuda igualmente a traçar uma estratégia de construção de uma imagem positiva. Por isso, as estruturas partidárias locais são essenciais na preparação de uma estratégia de campanha eleitoral nacional, pois podem ajudar o partido a mobilizar as pessoas e a recolher apoios. Para além disso, podem ajudar a criar nos eleitores locais um sentimento de pertença a um grupo, porque são convidados a participar nas iniciativas de campanha e a fomentar relações interpessoais com os militantes ou até com os próprios candidatos.

\section{Estudos sobre as campanhas eleitorais}

Existe a percepção de que as campanhas eleitorais têm algum impacto nas escolhas do eleitorado, sobretudo quanto mais disputadas forem as eleições e mais competitiva a luta eleitoral. Por isso tenta compreender-se como é que essa influência pode ser exercida, partindo de questões como as seguintes: quando e como é que o eleitor toma a sua decisão? Que critérios são privilegiados na escolha eleitoral? Como podem os candidatos influenciar os eleitores e como podem influenciar a imagem que os eleitores constroem deles? Tenta, assim, compreender-se a formação e a construção do processo de decisão eleitoral, incluindo vários fatores: o momento da escolha, hesitação, influência das imagens e mensagens, mobilização eleitoral, abstenção, reposicionamentos, fatores de indecisão, etc..

Mas os estudos sobre campanhas já contam com um longo histórico. Foram desenvolvidos na continuidade das pesquisas sobre propaganda e começaram por ocupar, no início, um importante espaço nos estudos da área da ciência política e do estudo do comportamento eleitoral. Mais tarde, este interesse alargou-se aos estudos da comunicação, e depois do campo da comunicação política se ter começado a afirmar, os estudos sobre as campanhas ganharam um novo impulso e são atualmente um domínio profícuo de investigação em todas estas áreas.

A justificação para a realização destes estudos reside no interesse de compreender a forma como os partidos se apresentam ao eleitorado e como procuram convencer os eleitores e assim captar o seu voto. Além disso, também podemos considerar a evolução da vida política atual, que tende a transformar-se numa "campanha permanente", apoiada em estratégias de comunicação cada vez mais elaboradas, outra razão importante para 
o interesse no estudo das campanhas eleitorais. O conceito de "campanha permanente" é da autoria de Sidney Blumenthal, que, em 1980, publicou a obra The permanent campaign, na qual fez uma análise do recurso ao marketing político e às sondagens em período eleitoral. Para Gerstlé, por seu lado, o interesse do estudo das campanhas eleitorais acentuou-se à medida que o espaço público se modernizou. "Esta modernização encorajou a ideia que as atitudes e os comportamentos políticos poderiam ser modificados num prazo mais curto de tempo do que se supunha anteriormente" (Gerstlé, 1992, p. 65).

Historicamente, podemos dizer que os efeitos da comunicação e das campanhas começaram a ser estudados no contexto da Primeira Guerra Mundial. O estudo das técnicas de propaganda recebeu um forte impulso através do presidente norte-americano Woodrow Wilson, que criou o Committee on Public Information com o objetivo de convencer a opinião pública das vantagens da participação dos Estados Unidos na guerra. Alguns anos mais tarde, em 1927, Lasswell publicou uma obra sobre as técnicas de propaganda durante a Primeira Guerra Mundial, impulsionando as metodologias de análise de conteúdo das mensagens, e nos anos trinta colaborou com o Institute for Propaganda Analysis, nos Estados Unidos da América. Isto significa que, simultaneamente ao recurso aos media de massa para transmitir mensagens políticas e propaganda, surgiu o interesse e a necessidade de compreender os seus efeitos.

A primeira teoria que surgiu sobre os efeitos foi a teoria hipodérmica ou dos efeitos totais. Temporalmente, esta teoria coincide com o período das duas guerras mundiais e com a difusão em larga escala das comunicações de massa. Representou a primeira reação de vários estudiosos à massificação da comunicação, que foi relacionada com as experiências totalitárias de alguns países, como a Alemanha, naquele período.

Esta teoria defendia uma relação direta entre a exposição às mensagens e o comportamento, o que significa que uma pessoa, desde que sofresse uma exposição à propaganda poderia ser controlada e manipulada num determinado sentido. Todos os media ofereceriam, assim, um discurso unitário e este seria aceite por todos da mesma forma, ignorando todas as outras possíveis influências e o fato de que as pessoas são diferentes e podem, por isso, reagir de forma diferente a um mesmo estímulo. O objetivo era tentar compreender os efeitos dos media numa sociedade de massa, mas não foi considerada a 
diversidade, quer dos vários tipos de media, quer das sociedades em que eles estão inseridos, bem como o peso das relações interpessoais.

A esta abordagem seguiram-se outras que enfatizaram precisamente o peso dos contextos da comunicação e tentaram especificar as condições e as limitações através das quais os media exercem os seus efeitos. Importantes desenvolvimentos foram realizados por Lazarsfeld e os seus colegas da Universidade de Columbia (1944) nos Estados Unidos da América, ao estudarem a formação da opinião pública em períodos eleitorais, o peso dos media, e a influência dos líderes de opinião. Para estes autores, os efeitos dos media seriam limitados e não totais, porque as pessoas têm tendência para rejeitar as mensagens que contradizem as suas próprias convicções e tendem a procurar informação que confirme as suas opiniões.

Na prática, os indivíduos estão protegidos dos efeitos dos media porque, antes de serem leitores ou telespectadores, eles são membros de uma família, habitam uma determinada zona geográfica, pertencem a uma classe social específica, têm preferências políticas, e pertenças culturais e religiosas, entre outras. A relevância das variáveis sociogeográficas é assim evidenciada na questão dos efeitos dos media e na explicação do processo de decisão de voto. Por outras palavras, todos estes elementos criam uma espécie de filtro que leva a que cada indivíduo tenha uma exposição seletiva às notícias e às comunicações eleitorais, e por isso a influência não é direta. No caso das campanhas eleitorais, os media provocavam, segundo estes autores, sobretudo o reforço, a ativação e a manutenção, em vez da alteração do sentido de voto. O principal fator de explicação do voto seria, desta forma, constituído por variáveis sociológicas, e a campanha eleitoral teria sobretudo o efeito de reforçar as predisposições políticas dos cidadãos.

Assim se construiu o "modelo dos efeitos limitados" da comunicação, dominante na década de 1960. Os efeitos são limitados no sentido de que a alteração de um voto no decurso da campanha eleitoral é muito rara e os efeitos reais da comunicação eleitoral são o reforço de atitudes pré-existentes, ou simplesmente a manutenção dessas atitudes. Neste modelo, são os fatores de longo termo que são primordiais na escolha de determinado partido ou candidato, como as variáveis sociológicas, e não os fatores de curto termo, como a campanha eleitoral.

Através deste tipo de estudos não foi possível sustentar efeitos fortes dos media e das campanhas no comportamento eleitoral porque se procuravam 
efeitos diretos de conversão. Contudo, como já vimos, convém não descurar a importância de outros efeitos, que podem ser tão ou mais importantes, como é o caso da influência indireta dos enquadramentos jornalísticos, da consonância e do reforço, determinantes na construção de percepções e de imagens sobre os atores e sobre os temas políticos, porque influenciam preferências e posicionamentos ideológicos e têm, por isso, potencial para influenciar o próprio sentido de voto.

Após alguns anos de domínio do modelo dos efeitos limitados, surgiram novas abordagens que provocaram alterações significativas no campo da investigação sobre os efeitos dos media. Um conjunto de pesquisas sobre o impacto da televisão e as análises de estratégias de discursos eleitorais (por exemplo, Politics and television de Lang e Lang, em 1968) ajudaram a promover uma alteração na perspectiva dos efeitos limitados. Chamou-se a atenção para a necessidade de olhar para os efeitos numa perspectiva de longo prazo, em vez de concentrar toda a atenção na conversão dos eleitores a partir da propaganda eleitoral e apenas nos períodos formais de campanha eleitoral. A perspectiva dos efeitos mínimos construiu-se no pressuposto de que os efeitos só se registavam no período de campanha e que os media e a comunicação eleitoral só teriam influência no comportamento eleitoral se ocorresse uma mudança no sentido de voto. Contudo, o papel preponderante que os media assumem na formação da opinião pública, selecionando e enquadrando os eventos e os fatos e comentando-os, é algo que ocorre de forma contínua, por isso o seu efeito é sobretudo indireto e de longo prazo.

Para além disso, nos tempos que correm torna-se difícil apontar datas precisas de começo das campanhas eleitorais, uma vez que, seguindo o conceito de "campanha permanente", os políticos cada vez mais traçam estratégias de longo prazo e de contato contínuo com as populações, sobretudo através dos media, numa tentativa de cultivar o apoio às suas propostas.

Compreende-se que estes dois fatores baralham os dados obtidos em estudos anteriores e tornam muito complicada a delineação de momentos claros e definidos em que ocorrerá a influência dos media e das campanhas. Um outro elemento fortalece a argumentação em torno dos efeitos indiretos e de longo prazo: vários autores referem a incontornável influência da mediatização na sociedade e na política (Mazzolini e Schulz, 1999; Silverstone, 1999; Salgado, 2007; Strömbäck, 2008; Strömbäck e Kaid, 2008; Strömbäck e Esser, 2009). 
A mediatização é uma teoria que sustenta que são os media que moldam e enquadram os processos e os discursos da comunicação política, bem como a sociedade em geral. Na verdade, a mediatização da política tem de ser vista como parte de um processo mais amplo, que é a mediatização da sociedade. O que o público vê, ouve e lê nos media influencia a sua visão do mundo e de si próprio e, consequentemente, a forma como age e reage aos acontecimentos. A frase de Silverstone "the media are becoming environmental" faz todo sentido neste contexto.

No caso da política, essa presença dos media detecta-se a vários níveis: primeiro, pelo grau de dependência da sociedade em relação aos media como veículo principal na obtenção de informação política. Segundo, na forma como os conteúdos mediáticos sobre a política seguem uma "lógica mediática" em detrimento de uma "lógica política”. E, por fim, pelo nível de adaptação dos discursos e dos comportamentos dos atores políticos aos media.

Alguns efeitos concretos da mediatização no exercício da política podem ser, por exemplo, os seguintes: a preponderância dos media como mediadores entre os políticos e os cidadãos, em detrimento dos partidos políticos; a aceleração dos tempos de decisão da política em algumas situações devido à pressão dos media e da opinião pública; a influência da função de agendamento dos media no estabelecimento de prioridades políticas; a simplificação do discurso político, que se adapta para ser veiculado pelos media; e uma crescente personalização da vida política, entre outros.

Subjacente a isto está a ideia de que, se os políticos querem transmitir as suas imagens e mensagens e chegar aos eleitores em geral, têm de se adaptar à linguagem dos media. Através dos media, o político alcança um maior número de cidadãos, muito maior do que pelos canais tradicionais da política, mas esse público é tão vasto como heterogêneo, do ponto de vista sociocultural, o que coloca o problema da perda da significação da mensagem política. Como resposta, os especialistas em comunicação e marketing político advertem para a necessidade do uso de frases curtas, da repetição da mensagem e da simplificação do discurso, através do recurso a um vocabulário repetitivo e limitando os termos raros e complexos. A conversão de ideias em eventos e de acontecimentos em narrativas são outras das alterações mais comuns na linguagem da política.

Os trabalhos de Jean-Marie Cotteret $(1991 ; 2000)$ mostraram a necessidade de o homem político insistir na repetição da mensagem, empobrecendo o seu 
discurso, recorrendo a um vocabulário pobre e repetitivo e limitando o uso de termos raros e complexos (a linguagem dos especialistas). As frases devem ser curtas e também deve ser dada uma especial atenção à rapidez da elocução. Assim, a complexidade inerente ao funcionamento da política parece servir de pretexto a uma descontextualização das mensagens políticas, porque simplificar as mensagens equivale a facilitar os contatos com a totalidade do eleitorado.

Há quem aponte as desvantagens deste tipo de procedimento e se refira a isto como a espetacularização da política, indicando que este tipo de democracia desvia as atenções dos debates que realmente interessam aos cidadãos, concentrando o foco da discussão em fait-divers. E que esta é uma das causas do desinteresse dos cidadãos pela política e dos crescentes níveis de abstenção em eleições.

Autores como Cappella e Jamieson (1997) e Patterson (1993; 2000) relacionam o desinteresse e o cinismo dos eleitores em relação à política com a forma como os media realizam as suas coberturas noticiosas das eleições e da política em geral, que denominam como coberturas estratégicas e negativas. Cappella e Jamieson identificam as seguintes características na cobertura noticiosa estratégica da política: são histórias com atores (políticos), críticos (jornalistas) e audiência (eleitores), em que existe uma centralidade do desempenho e estilo do candidato, um grande peso da divulgação das sondagens de opinião e da posição que os candidatos ocupam nelas, sendo frequente uma linguagem de competição, jogos e guerra.

Patterson (1993) apontou uma justificação para este tipo de cobertura noticiosa. $\mathrm{O}$ autor notou, com base em várias análises empíricas, que as notícias se têm tornado cada vez mais negativas e interpretativas, menos direcionadas para os temas e mais para a perspectiva de competição entre os políticos. Segundo ele, a emergência deste estilo de jornalismo agressivo coincidiu com o impacto da televisão comercial e com a divulgação cada vez mais frequente das sondagens de opinião. De fato, uma cobertura jornalística orientada pelas sondagens de opinião tem, geralmente, como resultado a redução drástica da discussão dos problemas políticos e sociais existentes num dado momento e dos enquadramentos dos próprios problemas, favorecendo a bipolarização. No caso de uma eleição, a publicação frequente de sondagens de opinião pode transformar o debate entre candidatos numa corrida ou num jogo, em que a principal preocupação é saber quem tem vantagem em termos de intenções de voto. 
Nestes casos, os órgãos de informação podem ajudar a acelerar a construção de candidaturas, ofuscar oponentes, silenciar candidatos com poucas probabilidades de ganhar, e até mesmo passar a ideia de que a eleição acabou antes mesmo do dia da eleição. Para além disso, a maneira como são divulgadas as sondagens de opinião pública pode também representar um obstáculo à mudança. Muitas vezes, a forma como as sondagens são apresentadas assemelha-se a uma consagração das posições maioritárias. Na sua obra intitulada Espiral do silêncio (1995 [1984]), Noëlle-Neumann explica que o receio do isolamento leva a maioria dos indivíduos a associar-se à posição dominante, o que, por sua vez, tem a consequência de silenciar as opiniões minoritárias. Ela acredita que as pessoas têm tendência para ocultar as suas opiniões se estas são diferentes das da maioria, ou seja, da opinião veiculada predominantemente pelos media, de forma a serem aceites.

No que respeita ao negativismo da cobertura noticiosa das campanhas eleitorais, Patterson (1993) identificou uma tendência crescente deste tipo de atitude em relação à política e explicou que esta alteração no tom da cobertura das campanhas foi, em grande medida, causada pela influência do jornalismo de estilo interpretativo. No estilo descritivo, a função dos jornalistas era simplesmente reportar os fatos e, por isso, grande parte da cobertura favorável que os candidatos recebiam derivava do que eles próprios haviam dito sobre as suas próprias candidaturas. O jornalismo interpretativo, pelo contrário, concede ao jornalista o papel de analista e, muitas vezes, até de “juiz". Neste tipo de cobertura, o jornalista atribui significado aos acontecimentos e às declarações dos atores políticos, fornecendo o contexto analítico e, por isso, está posicionado para moldar as notícias e fornecer sentido sobre elas, de uma forma que o jornalismo descritivo não permitia. Para além de um maior papel na construção do sentido das notícias, no jornalismo interpretativo a voz do jornalista tem também um peso crescente nos noticiários.

Outros tipos de estudos receberam um forte impulso e contribuíram também para consolidar a inflexão nas perspectivas sobre os efeitos dos media. Foi o caso, por exemplo, do estímulo aos estudos centrados na cultura das notícias, especialmente nos valores que os jornalistas e editores utilizam, enquanto gatekeepers, na decisão do que merece ser noticiado. Realizaram-se também estudos sobre a organização da campanha eleitoral, quer do lado dos partidos, quer do lado dos media. Neste caso, as pesquisas focaram o papel dos partidos políticos na campanha, os seus objetivos estratégicos, mas 
começaram a dar igualmente uma especial atenção à forma como as mensagens são trabalhadas para atingir estes objetivos e ao estudo dos suportes selecionados para as transmitir.

Uma outra corrente de pesquisa tem estudado os conteúdos das mensagens de campanha nos diferentes canais de comunicação, como é o caso da quantidade de peças jornalísticas publicadas e transmitidas nos órgãos de informação, o balanço partidário na imprensa, o tom positivo ou negativo dos conteúdos veiculados nos diversos suportes, o agendamento dos assuntos de campanha e ainda a representação dos candidatos minoritários nos media.

Neste contexto também é relevante a posição de autores, como Popkin (1991), que apontam para a ideia de que os eleitores utilizam atalhos, como os media ou a opinião das pessoas em quem confiam, para formar o seu conhecimento político. Somado a isso, os eleitores constroem as suas atitudes e preferências políticas todos os dias, através da sua vivência diária e da sua experiência com as instituições políticas, julgando, por exemplo, a atuação governamental em matérias como a saúde, a segurança, ou a educação ou, por outro lado, a resposta da oposição em fornecer propostas alternativas à atuação do Governo, especialmente em caso de crise, mas não só.

Estas teorias suportam a ideia de que os efeitos de longo termo que decorrem das campanhas permanentes, que servem para construir uma imagem de confiança, não são esquecidos e são muito importantes no momento da decisão de voto. Contudo, se estes estudos sustentam a existência de efeitos para além do período formal da campanha, eles não apontam para uma diminuição de interesse nas campanhas eleitorais. Estas continuam a ser extremamente importantes, para os políticos e para os media, mas também para os cidadãos, pois são momentos singulares de transmissão de informação política, de implementação de estratégias políticas e de comunicação, bem como de interação entre os diferentes atores, pelo que criam situações de inigualável interesse para o estudo da evolução da política e da qualidade da democracia num país.

Depois, convém também não esquecer os segmentos de eleitores que são influenciados pelo período formal de campanha, pois muitas pessoas esperam pelos dias de campanha intensa antes das eleições para decidir o seu sentido de voto. Estes late deciders e indecisos procuram na campanha pistas e estímulos que os ajudem a tomar uma decisão. Como alguns destes eleitores são mais inconsistentes e reagem a estímulos emocionais, muitas 
vezes associa-se este tipo de atitude a um comportamento pouco sofisticado da política, mas alguns autores discordam referindo que estes eleitores procuram apenas informar-se durante o período oficial de apresentação das propostas dos partidos e de intensificação do combate de ideias.

Em suma, a quase total focalização nos políticos e no estudo das suas estratégias políticas deu lugar à ideia de que a comunicação política e eleitoral é fortemente influenciada por fatores exógenos aos políticos, como os media, tendo-se verificado uma tentativa de incluir esses elementos no processo e de estudar a sua influência na política e na campanha. Neste sentido, a comunicação política resulta essencialmente da interação entre vários protagonistas: os políticos, os media e o eleitorado. Os media são vistos como representantes de um papel mais autônomo do que no passado, não refletindo apenas o processo eleitoral mas também modelando esse mesmo processo. Além disso, a análise dos efeitos das campanhas passa a ser realizada não apenas ao nível dos resultados eleitorais imediatos (quem ganha ou perde as eleições), mas também a nível de prováveis redefinições das situações políticas e dos partidos, consequências diretas ou indiretas das campanhas e das eleições.

\section{A campanha eleitoral: construção de significados políticos a partir das interações dos atores}

Neste contexto, é importante enfatizar a ideia de que aceitar que os media se tornaram um dos espaços privilegiados da política não significa defender que toda a política possa, doravante, ser reduzida a soundbytes, imagens, sons ou manipulações simbólicas. Porque, não obstante os media serem atualmente um dos principais, senão o principal palco da política, esta mantém ativas as suas estruturas de decisão e de influência fora dos media, e as candidaturas políticas e as campanhas eleitorais, mais do que absolutamente determinadas pelos media ou pela política, resultam de processos de interação e de construção entre ambos, não esquecendo obviamente um outro elemento fulcral: os eleitores.

A estratégia para participar na competição eleitoral é originada pelos atores políticos, pela liderança dos partidos políticos e os seus conselheiros, mas é moldada pelos media e pelo contexto organizacional da campanha e também pelo ambiente geral em que decorre a campanha (a hostilidade da imprensa em relação a um dos partidos, ou a revelação de um escândalo 
relacionado com um dos candidatos durante a campanha, são possíveis fatores de influência, entre outros). Depois, também os eleitores são atores na campanha porque são chamados a participar em algumas ocasiões, por exemplo, em sondagens de opinião e em iniciativas de campanha, o que também deve ser considerado como um possível fator de influência, pois pode ter efeitos sobre os outros atores. As campanhas eleitorais modernas são, desta forma, eventos altamente mediatizados, em que a reação dos media, as respostas organizacionais e a opinião dos eleitores são todas igualmente incluídas no processo e têm capacidade para o influenciar.

Os políticos tentam controlar ao máximo as suas mensagens e imagens, que têm de ser estrategicamente calculadas no contexto da sua campanha e tentam incorporar na sua estratégia os acontecimentos inesperados que também podem ter impacto na opinião dos eleitores. Obviamente, é mais fácil controlar as mensagens que são transmitidas pelos candidatos e pela organização da campanha do que as mensagens e as avaliações que os media fazem do desempenho dos candidatos, das suas possibilidades de vencer a eleição, da forma como estão a decorrer as iniciativas de campanha, ou as críticas e ataques dos adversários. Por outras palavras, é fácil perceber que um candidato estará muito mais exposto numa entrevista ou num debate em direto, do que num jantar com apoiantes, ou num comício onde tudo foi pensado para passar uma boa imagem.

Seguindo a sua própria gramática e lógica de funcionamento, os media tratam os detalhes da campanha eleitoral que são mais atrativos para os seus públicos, ainda que possa existir, em alguns casos, alguma preocupação relativa à equidade no tratamento da transmissão da campanha dos diferentes partidos. Os media estabelecem as prioridades noticiosas porque prestam atenção a uns assuntos, ignorando outros, através de processos como o gatekeeping, ou o agenda setting, por exemplo. Os editores agem como gatekeepers sobre a informação que recolhem, avaliando-a a partir de critérios de noticiabilidade definidos previamente, como a proximidade geográfica, a negatividade, ou o carácter inesperado do fato, entre outros, e selecionam o que merece atenção e consequentemente deve ser publicado.

Através do agendamento, os media decidem não apenas os temas importantes num determinado momento, mas também o grau de atenção que o público lhes deve dedicar. Depois da seleção do que deve ser publicado, não é indiferente noticiar um tema nas páginas interiores de um jornal, ou no 
fim do alinhamento de um jornal televisivo, ou dar-lhe destaque de primeira página ou de tema de abertura do telejornal, por exemplo. O espaço dedicado ao tratamento do tema, a ilustração com imagens, ou o fato de se lhe conceder mais recursos técnicos e humanos, são outros exemplos de como o trabalho jornalístico pode hierarquizar a matéria considerada noticiável. Na prática, para o público em geral, estes elementos funcionam como indicadores do grau de importância que têm os temas num determinado momento.

É importante ter a noção, todavia, que o agendamento dos media pode ser - e geralmente é - influenciado e, por vezes, até controlado pelas agendas de outros atores. Afirmar que os media determinam a agenda do público não significa atribuir todo esse poder aos jornalistas, uma vez que, muitas vezes, eles próprios são alvo de pressões e sofrem influências em relação ao que devem publicar e à forma como o devem fazer. E isto acontece quer em democracias emergentes, quer em democracias consolidadas, ainda que estas pressões possam definir-se de diferentes contornos num caso ou no outro.

Este sobreaviso não impede, contudo, a conclusão de que, ao determinar que assuntos são importantes e quais merecem atenção, os meios de comunicação social adquirem um papel importante na estruturação da realidade política e social. Por outras palavras, o público não só toma conhecimento dos assuntos pelos media, como também percebe que importância deve dar a cada assunto, através da ênfase conferida pelos media. E, em contextos eleitorais, isto poderá ter uma importância tanto maior quanto mais renhida for a luta dos partidos em campanha. Por exemplo, os media podem noticiar sobre eventuais escândalos envolvendo um dos candidatos, ou concentrar a atenção em temas que são mais favoráveis a um partido.

Isto significa que existem formas possíveis de influenciar a imagem dos candidatos e a campanha através da cobertura jornalística, mesmo que não se declare o apoio direto a um partido, ou se transmita a sua propaganda eleitoral com enviesamento positivo. O conceito de enquadramento chama a atenção para a transformação da mensagem política inicial, porque o tratamento jornalístico a que esta é sujeita encoraja determinadas percepções e interpretações nos eleitores. Isto significa que o discurso político sofre alterações para ser transmitido através dos media, o que pode ser entendido como uma coedição da mensagem política entre os políticos e os jornalistas. Mas também os eleitores têm algo a acrescentar a esse processo, pois os enquadramentos propostos pelos media e pelos políticos são, por sua 
vez, influenciados pela própria experiência pessoal dos receptores. Vários estudos (ver, por exemplo, os trabalhos de Sonia Livingstone) apontam para a recepção diversificada das audiências, porque estas interpretam um mesmo conteúdo de formas diferentes, consoante as suas próprias vivências, posicionamentos e preferências.

Assim, podemos assumir que os media são importantes e eventualmente poderosos durante uma campanha eleitoral, não porque têm a capacidade de mudar de forma direta os votos num partido, mas porque uma simples notícia pode chamar a atenção para um candidato, ou para um aspecto particular da campanha e, dessa forma, permitir uma reformulação da atitude do eleitor, influenciar a sua percepção sobre o ambiente da campanha, ou sobre a mensagem ou a imagem de um candidato.

Para além destes, existem outros aspectos em que se verifica a influência dos media. O processo editorial de seleção da informação dá geralmente uma versão condensada da campanha. Uma das mais importantes consequências da elaboração dos noticiários jornalísticos, e em especial o televisivo, no qual a mensagem surge ainda mais fragmentada, sobre a campanha eleitoral é a amplificação dos excertos escolhidos para transmissão. Estes extratos selecionados representam, para os eleitores e para o público em geral, a essência e a peça fulcral da mensagem de origem partidária, e esta foi selecionada pelos media.

Outro aspecto fundamental da organização da campanha eleitoral feita pelos órgãos de informação prende-se com a tentativa constante de estabelecer um confronto, criando um contraponto entre os partidos e os candidatos rivais: como se os jornalistas estivessem a tentar criar uma espécie de diálogo entre os partidos que, de outro modo, podia não existir, e levando os candidatos a comentários e ações que, de outra forma, poderiam não ocorrer. Mais uma vez, este processo ganha maior peso na televisão, pois o tempo de reação é mais curto e permite o confronto permanente, o que não significa que não ocorra também na imprensa escrita.

Há ainda outro tipo de influência, a dos media sobre o comportamento dos políticos e sobre a prática política, e a possível influência destas alterações sobre os eleitores também não deve ser descurada. Só para citar alguns exemplos, já foram mencionados fatores como a simplificação das mensagens políticas e a encenação que a mensagem política sofre para se tornar mais facilmente notícia, mas existem outros igualmente relevantes, como a importância da imagem dos candidatos. 
Diversos autores acreditam que os media, e em especial a televisão, afetaram os critérios de escolha dos candidatos e líderes políticos. Depois da sua própria experiência, o próprio presidente norte-americano Richard Nixon explicou que "a televisão transformou a forma como a liderança política é exercida e mudou o tipo de pessoa que pode ter expectativas de vencer uma eleição" (Nixon, 1982, p. 342). Para além disso, as próprias campanhas passaram a ser organizadas de forma diferente com vista à sua adaptação aos media, e as iniciativas de campanha passaram a ser cuidadosamente planejadas para provocar bons momentos mediáticos. Por exemplo, os comícios incluem momentos musicais e de entretenimento para motivar a assistência e são organizados em crescendo, de forma a tudo culminar no momento forte que é o discurso do líder. Atualmente, pode afirmar-se que as campanhas são planejadas de forma a que o candidato consiga o maior tempo possível de exposição mediática, pois, dessa forma, fará chegar a sua mensagem a um maior número de pessoas, aumentando, assim, a probabilidade de conseguir mais votos ou, pelo menos, de tornar mais conhecidos os seus pontos de vista.

\section{Conclusões}

As campanhas eleitorais são momentos cruciais para as democracias, quando os eleitores escolhem entre os candidatos e os seus programas políticos. Por sua vez, a informação chega ao eleitorado sobretudo a partir da cobertura que os media fazem das iniciativas de campanha. As campanhas são um processo dinâmico entre os partidos, os candidatos e os seus consultores, os media e os cidadãos. As interações entre eles são essenciais para determinar o curso dos acontecimentos.

Os media são importantes fontes de conhecimento e de apreciação acerca da forma como se desenrolam os processos eleitorais, porque dão a conhecer as últimas notícias e permitem ao eleitor saber como decorre a campanha dos vários candidatos e partidos. Mas, mais do que veículos de transmissão da mensagem e palcos onde os acontecimentos se desenrolam, os media agem sobre as mensagens e influenciam as imagens dos políticos.

Os candidatos necessitam dos meios de comunicação social porque o eleitorado espera que os jornais, a televisão e a rádio lhes forneçam informações sobre a campanha e os candidatos. Desta forma, os candidatos sabem que a sua presença nos media pode facilitar a transmissão da sua mensagem. Além disso, o fato de conseguirem exposição nos media confere-lhes visi- 
bilidade e, no caso dos serviços informativos, alguma credibilidade à sua mensagem, através do processo de mediatização. Este processo pressupõe que a mensagem eleitoral passou pelo cunho de veracidade dos jornalistas, ou seja, recebeu o tratamento jornalístico de verificação. A questão do descrédito de que sofre, atualmente, a classe jornalística é um outro problema, que carece de atenção própria.

Os media determinam o que é notícia e que candidatos ou assuntos merecem destaque, o que leva, por sua vez, os candidatos a orientarem as suas campanhas de forma a serem notícia, acontecimento, provocando "momentos fotográficos”, transformando fatos em narrativas, ou seja, criando momentos que originam uma cobertura dos media, com imagens passíveis de despertar a atenção primeiro do jornalista e, através deste, do eleitorado. Por isso, é tão importante para os candidatos saber como funcionam os media, os seus suportes e linguagens, e rodear-se dos melhores assessores de imagem e de comunicação, com o objetivo de se adaptarem à lógica dos media e serem bem-sucedidos na transmissão da sua mensagem. Mas não só as estratégias de contato dos políticos com as populações são cada vez mais elaboradas e apoiadas nos media como a preparação para eleições começa muito antes do período oficial de campanha.

A par dos argumentos que sustentam que as campanhas podem ter os efeitos referidos, as campanhas também são constantemente criticadas por não serem suficientemente elucidativas para os eleitores e por representarem mais uma luta de personalidades do que a apresentação e a discussão de propostas para os problemas do país. A forma como os media realizam a cobertura da política e das campanhas também não é isenta de críticas. Foi referida a perspectiva de Cappella e Jamieson sobre a espiral do cinismo que as coberturas estratégicas provocam, bem como a perspectiva de Patterson sobre a crescente negatividade e interpretação dos jornalistas na informação sobre a política. Ou seja, a forma como a política é retratada nos media terá efeitos consideráveis na abstenção e no desinteresse dos cidadãos pela política.

Em suma, as campanhas não serão suficientemente esclarecedoras para que os eleitores façam escolhas informadas, e a culpa é do discurso político, que é cada vez mais pobre, mas também do trabalho dos jornalistas, que optam a maior parte das vezes por uma cobertura estratégica da política, onde dão ênfase à competição, às sondagens, à forma como decorrem as iniciativas de campanha, em vez de colocar a tônica nas propostas dos candidatos 
e na contextualização das eleições e dos temas debatidos, o que contribui, segundo alguns autores, para uma espiral de cinismo, como já vimos, e para a degradação da qualidade do discurso político.

Os elementos explorados neste artigo ajudam a compreender a influência que os meios de comunicação exercem na mensagem política e sugerem a conclusão de que esta sofre alterações. Por esta razão, são tão importantes os estudos sobre a cobertura mediática das campanhas eleitorais. Não só porque os meios de comunicação são a melhor forma - e, muitas vezes, a única - de o cidadão comum tomar contato com a campanha eleitoral dos vários partidos políticos, mas também porque, se a mensagem política sofre alterações (algumas da responsabilidade dos políticos, outras dos próprios media) para ser objeto de tratamento mediático e de transmissão nos seus suportes, deve ser aprofundado o estudo destas influências e avaliados os possíveis efeitos que essas alterações têm nos diversos atores.

\section{Referências bibliográficas}

BENNETT, Lance \& ENTMAN, Robert (2001). Mediated politics: communication in the future of democracy. Cambridge: Cambridge University Press.

CAPPELLA, Joseph \& JAMIESON, Kathleen (1997). Spiral of cynicism. New York: Oxford University Press.

COTTERET, Jean-Marie (1991). Gouverner c'est paraître. Paris: PUF. (2000). La magie du discours: précis de rhétorique audiovisuelle. Paris: Michalon.

DAYAN, Daniel \& KATZ, Elihu (1992). Media events: the live broadcasting of history. Cambridge: Harvard University Press.

GERSTLÉ, Jacques (1992). La communication politique. Paris: PUF.

GUNTHER, Richard \& MUGHAN, Anthony (2000). Democracyand the media: a comparative perspective. Cambridge: Cambridge University Press.

HESS, Stephen (1988). The presidential campaign: an essay. Washington: The Brookings Institution.

IYENGAR, Shanto \& REEVES, Richard (1997). Do the media govern?: reporters, politicians and the American people. Thousand Oaks, CA: Sage.

LAZARSFELD, Paul; BERELSON, Bernard \& GAUDET, Hazel (1944). The people's choice: how the voter makes up his mind in a presidential campaign. New York: Columbia University Press. 
MANIN, Bernard (1996). Principes du gouvernement representative. Paris: Flammarion.

MAZZOLINI, Gianpietro \& SCHULZ, Winfried (1999). "Mediatization of politics: a challenge for democracy?". Political Communication, n. 16, p. 247-261.

McCOMBS, Maxwell \& SHAW, Donald L. (1972). "The agenda-setting function of mass media”. Public Opinion Quarterly, n. 36, p. 176-187.

McCOMBS, Maxwell \& WEAVER, David (1997). Communication and democracy: exploring the intellectual frontiers in agenda-setting theory. New Jersey: Erlbaum.

MEYER, Thomas (2002). Media democracy: how the media colonize politics. Cambridge: Polity.

MUGHAN, Anthony (1978). "Electoral change in Britain: the campaign reassessed”. British Journal of Political Science, n. 8, p. 245-253.

NIXON, Richard (1982). Leaders. New York: Warner.

NOËLLE-NEUMANN, Elisabeth (1973). "Return to the concept of powerfull mass media”. Studies of Broadcasting, n. 9, p. 67-112.

(1995 [1984]). La espiral del silencio, opinión pública: nuestra piel social. Barcelona: Paidós.

PATTERSON, Thomas (1993). Out of order: how the decline of the political parties and the growing power of the news media undermine the American way of electing presidents. New York: Knopf.

(2000). "Serão os media noticiosos actores políticos eficazes?". Revista de Comunicação e Linguagens, n. 27, p. 75-96.

POPKIN, Samuel (1991). The reasoning voter. Chicago: University of Chicago Press.

PORTO, Mauro (2004). "Enquadramentos da mídia e política”, em RUBIM, Albino (org.). Comunicação e política, conceitos e abordagens. Salvador: EdUFBA/ Unesp.

SALGADO, Susana (2007). Os veículos da mensagem política: estudo de uma campanha eleitoral nos media. Lisboa: Horizonte.

(2010). Os candidatos presidenciais: construção de imagens e discursos nos media. Coimbra: Minerva Coimbra.

SILVERSTONE, Roger (1999). Why study the media? London: Sage.

STRÖMBÄCK, Jesper (2008). "Four phases of mediatization: an analysis of 
the mediatization of politics". The International Journal of Press/Politics, v. 13, n. 3, p. 228-246.

STRÖMBÄCK, Jesper \& ESSER, Frank (2009). “Shaping politics: mediatization and media interventionism”, em LUNDBY, Knut (ed.). Mediatization: concept, changes, consequences. New York: Peter Lang.

STRÖMBÄCK, Jesper \& KAID, Lynda (ed.) (2008). The handbook of election news coverage around the world. New York: Routledge.

SWANSON, David \& MANCINI, Paolo (ed.) (1996). Politics, media and modern democracy, an international study of innovations in electoral campaigning and their consequences. Westport: Praeger.

\title{
Resumo:
}

Neste artigo teórico abordam-se as influências que a política e as campanhas eleitorais sofrem devido à sua cobertura mediática. As campanhas eleitorais são momentos privilegiados da vida política democrática, onde se encetam esforços para transmitir mensagens e persuadir através da comunicação política. Os media são, nas sociedades mediatizadas, a principal forma de contato dos eleitores com a política, mas, mais do que transmissores neutros das mensagens políticas, os media agem sobre a forma e o conteúdo da política. Consideram-se dois níveis de influência dos media, um primeiro sobre as formas de fazer campanha e de transmitir as mensagens, e um segundo sobre os eleitores, na construção de imagens e percepções que estes têm da política e dos políticos e no comportamento eleitoral.

Palavras-chave: campanhas eleitorais; media; partidos políticos; candidatos.

\begin{abstract}
:
This theoretical article approaches the influences politics and electoral campaigns experience due to media coverage. Electoral campaigns are privileged moments in a democracy, where efforts are made to convey messages and persuade through political communication. The media are, in mediatized societies, the main source of information for most of the voters, but more than just mere neutral vehicles, they influence political messages. Two levels of media influence are taken into account, a first related with the ways of campaigning and messages' dissemination, and a second related with voters, in the construction of images and the perceptions voters have of politics and in electoral behavior.
\end{abstract}

Key words: electoral campaigns; media; political parties; candidates.

Recebido em $1^{\circ}$ de setembro de 2011.

Aprovado em 10 de junho de 2012. 